\title{
O Plano de Desenvolvimento da Educação no contexto do novo desenvolvimentismo brasileiro
}

\author{
The Education Development Plan in teh context of the brazilian new \\ developmentalism \\ El Plan de Desarrollo de la Educación en el contexto del nuevo desarrollo \\ brasileño

\section{CECÍLIA CAROLINA SIMEÃO DE FREITAS} \\ MARCELO SOARES PEREIRA DA SILVA
}

\begin{abstract}
Resumo: O presente artigo se propõe discutir as bases da perspectiva do novo desenvolvimentismo que balizou as políticas públicas implementadas no Brasil no período de 2003 a 2010, ao mesmo tempo em que situou nesse contexto o Plano de Desenvolvimento da Educação (PDE) e o planejamento educacional. A partir de uma revisão de literatura e cuidadosa análise dos documentos que orientam o PDE, evidencia como no se fez presente campo da educação uma matriz discursiva que, mais uma vez, afirmava o planejamento como estratégia vinculada ao modelo de desenvolvimento econômico em curso.
\end{abstract}

Palavras-chave: Política educacional; novo desenvolvimentismo; planejamento educacional.

\begin{abstract}
This article aims to discuss the foundations of developmental new perspective that buoyed public policies implemented in Brazil from 2003 to 2010, while it placed the Plano de Desenvolvimento da Educação (PDE - Education Development Plan) and educational planning in this context. From a literature review and careful analysis of the documents that guide the PDE, it shows how in the field of education a discursive matrix was present, and that once more, shows planning with strategy linked to the current economic development model.
\end{abstract}

Keywords: Educational politics; new developmentalism; educational planning.

Resumen: Este articulo se propone a discutir las bases de la perspectiva de nuevo desarrollo que demarcó las políticas públicas practicadas en Brasil durante el período de 2003 a 2010, al mismo tiempo en que sucedió el Plan de Desarrollo de la Educación (PDE) y la planificación educativa en este contexto. A partir de una revisión de la literatura y el análisis cuidadoso de los documentos que orientan la PDE, muestra como en el campo de la educación se hizo presente una matriz discursiva, que una vez más afirmaba la planificación como estrategia vinculada al modelo de desarrollo económico actual.

Palabras clave: Política educativa; el nuevo desarrollo; planificación educativa. 


\section{INTRODUÇÃO}

A chegada de Luiz Inácio Lula da Silva (2003-2010) ao poder central, após a vitória no pleito eleitoral de 2002, significou importante conquista para determinados setores da sociedade brasileira, após oito anos de dois mandatos consecutivos de Fernando Henrique Cardoso (1995-1998; 1999-2002). Isso porque, de um lado, ) chegava ao poder central uma nova coalizão partidária, tendo o Partido dos Trabalhadores à frente, e formada pelo Partido Comunista do Brasil (PCdoB); o Partido Liberal (PL); o Partido da Mobilização Nacional (PMN) e o Partido Comunista Brasileiro (PCB, rompendo um ciclo partidário de poder que tinha o Partido da Social Democracia Brasileira (PSDB) e o Partido Democratas (DEM) à frente. De outro lado, porque tomava força na política nacional uma matriz discursiva que assinalava a perspectiva de se aliar crescimento econômico e inclusão social ou, de outra forma, desenvolvimento econômico e desenvolvimento social.

Essa perspectiva estava delineada no Programa de Governo anunciado pela candidatura de Lula e orientou a maior parte dos discursos proclamados em torno das políticas implementadas entre 2003 e 2010. Nesse contexto, assumiram destaque o planejamento governamental em geral e o planejamento educacional em particular pela relevância das ações de planificação desencadeadas nesse período sob a égide de um novo modelo de desenvolvimento prognosticado pelo Governo Lula.

Este artigo discute alguns dos elementos que marcaram esse período de governo, de modo a compreender a perspectiva neodesenvolvimentista que orientou as políticas públicas implementadas e sua articulação com as políticas educacionais colocadas em curso, com destaque para o Plano de Desenvolvimento da Educação e, no seu âmbito, do Plano de Ações Articuladas. Para tanto, num primeiro momento, localiza as bases que deram sustentação a essas políticas, expressas no Programa de Governo anunciado por Lula da Silva e no Plano de Aceleração do Crescimento; sua articulação com a perspectiva do novo desenvolvimentismo que predominou no país naquele momento e seus desdobramentos no campo das políticas educacionais.

\section{ADENTRANDO OS GOVERNOS LULA (2003-2010) A PARTIR DE UMA ANÁLISE DE SEU PROGRAMA DE GOVERNO}

No Programa de Governo da candidatura de Lula da Silva, sob o título Um Brasil de Todos - Crescimento, Emprego e Inclusão Social, apresentado à sociedade brasileira no pleito de 2002, era anunciada a necessidade de se "mudar o rumo do 
Brasil" com vistas à "implantação de um modelo de desenvolvimento alternativo, que tem o social por eixo" (Coligação Lula Presidente, 2002, p. 2). Ao mesmo tempo, era afirmado que esse modelo de desenvolvimento alternativo deveria ocorrer sustentado em "um novo contrato social" (Ibidem).

Só um novo contrato social que favoreça o nascimento de uma cultura política de defesa das liberdades civis, dos direitos humanos e da construção de um País mais justo econômica e socialmente permitirá aprofundar a democratização da sociedade, combatendo o autoritarismo, a desigualdade e o clientelismo. $\mathrm{Na}$ busca de um novo contrato, a mobilização cívica e os grandes acordos nacionais devem incluir e beneficiar os setores historicamente marginalizados e sem voz na sociedade brasileira. Só assim será possível garantir, de fato, a extensão da cidadania a todos os brasileiros. É indispensável, por isso, promover um gigantesco esforço de desprivatização do Estado, colocando-o a serviço do conjunto dos cidadãos, em especial dos setores socialmente marginalizados. (Ibidem).

Ainda no delineamento desse novo contrato social, o documento em análise destacava a necessidade de um novo pacto federativo, que, ao mesmo tempo, assegurasse autonomia dos entes - União, estados e municípios - e o equilíbrio na relação entre eles.

Esse Programa de Governo estava estruturado em quatro grandes eixos temáticos: Crescimento, Empregoe InclusãoSocial;Desenvolvimento, Distribuição de Renda e Estabilidade; Inclusão Social e Infraestrutura e Desenvolvimento Sustentável. Em vários momentos do documento, era reafirmada a articulação entre desenvolvimento social e desenvolvimento econômico, destacando-se, para tanto, a necessidade de se construir uma nova lógica na formulação e condução das políticas sociais, caracterizada pela integração das ações de diferentes áreas, num processo que favoreça o estabelecimento de políticas intersetoriais. Eis como esse aspecto está apresentado no Programa de Governo do candidato Lula:

A implementação de políticas sociais como eixo do desenvolvimento exige medidas audaciosas e criativas. As políticas sociais quase sempre foram tratadas no Brasil como questões marginais, vinculadas ao assistencialismo. Para mudar essa lógica, o primeiro passo é romper com as ações fragmentadas e dispersas, os feudos e loteamentos temáticos e clientelísticos que descaracterizam as políticas sociais no Brasil em todas as esferas, do município à União. O País precisa de políticas sociais integradas, estratégicas, formuladas e implementadas por meio de ações intersetoriais, buscando sempre parcerias com os diversos segmentos, entidades e movimentos sociais. (Idem, p. 39)

Especificamente no que se refere à educação e sua relação com o desenvolvimento, era evidenciado seu papel como uma das estratégias para enfrentamento da fragmentação social.

É vital recuperar a rede pública, tanto no nível fundamental quanto no médio e 
nas universidades, valorizando principalmente a qualidade. Uma boa formação da juventude colabora para a retomada do desenvolvimento sustentável, além de ser um diferencial para a competição do País no mercado internacional. A educação de qualidade é fator de emancipação e cidadania, contribui para que os jovens se integrem ao mercado de trabalho e evita a fragmentação social que alimenta a violência e o crime organizado. [...] Para o Brasil manter a coesão social, precisará combinar o combate implacável contra a criminalidadem ao investimento estratégico em educação. Só assim o Estado voltará a ter o respeito dos cidadãos. Só assim a sociedade reforçará a crença nas instituições e o respeito aos marcos legais. (PROGRAMA DE GOVERNO, 2002, p. 15)

Quanto à política educacional a ser implementada pelo novo governo, era afirmado no seu Programa que "todos os elos educacionais, da creche à pós-graduação, têm de ser verdadeiras prioridades e contar com recursos progressivamente maiores" (Idem, p. 46). No que se refere aos elementos gerais orientadores dessa política, foram apontados os seguintes aspectos: prioridade para a universalização da Educação Básica, abrangendo da educação pré-escolar ao nível médio, acompanhada da garantia de acesso à creche; ampliação do Fundef ${ }^{1}$ para toda a educação básica; criação do sistema nacional articulado de educação; ampliação das vagas nas universidades públicas e reformulação do sistema de crédito educativo (Ibidem).

Mais uma vez, a educação era afirmada como "instrumento para a promoção da cidadania", mas, "sobretudo nos dias de hoje, instrumento fundamental para o desenvolvimento e a inserção competitiva de qualquer nação no mundo" (Idem, p. 44). Observe-se que essa maneira de compreender o papel e o lugar da educação na agenda pública não vai além das perspectivas políticas já presentes na sociedade brasileira e nas sociedades capitalistas em geral, uma vez que coloca a educação e a formação da juventude como um dos requisitos para o desenvolvimento e inserção das novas gerações no mercado de trabalho. Nesse sentido, a lógica liberal conservadora se mantém como orientadora nas propostas de políticas de educação apresentadas à sociedade brasileira.

A perspectiva inaugurada em 2002 se manteve em 2006, agora, porém. com maior ênfase no crescimento econômico articulada a uma perspectiva de planejamento na gestão pública. Na esteira das ideias já apresentadas em 2002, no sentido de se afirmar um modelo de desenvolvimento econômico com políticas sociais que diminuíssem a exclusão social, o segundo mandato de Lula da Silva à frente do executivo federal foi marcado pelo anúncio do Programa de

1 O Fundo de Manutenção e Desenvolvimento do Ensino Fundamental e de Valorização do Magistério (FUNDEF) foi instituído pela Emenda Constitucional n. ${ }^{\circ} 14$, de setembro de 1996, e regulamentado pela Lei n. ${ }^{\circ}$ 9.424, de 24 de dezembro do mesmo ano, e pelo Decreto nº 2.264, de junho de 1997. 
Aceleração do Crescimento (PAC), apresentado como um conjunto de metas para estabelecimento de um crescimento sustentável com vistas à inclusão social e à distribuição de renda.

De acordo com o que fora anunciado pelo executivo federal, o PAC objetivava enfrentar as principais causas que embaraçavam o crescimento do país, melhorando a infraestrutura, como a de energia e transportes, e aumentando o crédito para o financiamento dos investimentos, além de estabelecer estratégias para matérias regulatória, fiscal e tributária. Diferentemente das outras ações até então estabelecidas pelo Governo Lula, o PAC destacava-se, por seu aspecto estratégico, transversal, complexo e intersetorial, como forma de fazer política econômica em uma linha definida pelo Estado, envolvendo diversos órgãos do poder público federal em articulação com os governos estaduais, municipais e o do Distrito Federal.

Com efeito, nos discursos e propostas formuladas ao longo do Governo Lula, a proposta de um novo modelo de desenvolvimento está relacionada com o planejamento. Sempre registrado nos documentos oficiais, é possível verificar na Mensagem ao Congresso de 2008, após o lançamento do PAC, como foi colocada a importância da visão estratégica de curto, médio e longo prazo para a conquista de credibilidade no âmbito do mercado, destacando o papel do Estado como indutor do crescimento.

Para ser bem-sucedido, o PAC demanda a recuperação da capacidade de planejamento de longo prazo e de gestão de investimentos por parte do setor público. A retomada da capacidade de planejamento e investimento pelo Governo, catalisada pelo PAC, aumentou o nível de confiança na economia brasileira, acelerando as decisões de investimento do setor privado. (BRASIL, 2008, p. 17)

Ao lado dessa matriz discursiva, entre 2008 e 2009 o comportamento do Poder Executivo Federal foi priorizar as ações estratégicas do PAC nas dimensões social e econômica com um portfólio de projetos que objetivaram, em linhas gerais, a geração de emprego e renda, o crédito imobiliário, o fortalecimento da infraestrutura econômica, por meio de investimentos e modernização dos setores de energia, transporte, telecomunicações, saneamento e recursos hídricos, buscando ampliar a oferta e desenvolver o equilíbrio macroeconômico. Essa definição interferia diretamente na harmonização do sistema capitalista via política anticíclica. Segundo dados apresentados pelo Instituto de Pesquisas Econômicas Aplicadas (IPEA), as empresas estatais foram responsáveis por mais de 31\% dos investimentos no âmbito do PAC, o que possibilitou o incremento de crédito na economia brasileira através da execução do PAC. Assim, 
Com o PAC, o Estado deixa de ser um mero definidor de regras para o setor privado e reassume seu papel fundamental de indutor dos investimentos. A sua primeira versão estimou investimentos da ordem de R \$ 503,9 bilhões, até 2010, em infraestrutura nas áreas de saneamento, habitação, transporte, energia e recursos hídricos. Para ajudar a minimizar os efeitos da crise externa de 2008 sobre a economia brasileira, e como parte das políticas anticíclicas, o valor foi elevado posteriormente para $\mathrm{R} \$ 656,6$ bilhões. Até maio de 2010, R \$ 463,9 bilhões, o equivalente a 70,7\% do montante total, haviam sido investidos (IPEA, 2010, p. 47)

Para a análise dessa postura mais presente do Estado na condução da política econômica, em torno de um projeto societal sob o prisma do novo desenvolvimento, é oportuno o ponto de vista de FALEIROS (1991) "o Estado não se encontra fora ou acima da sociedade, mas é atravessado pelas forças e lutas sociais que condicionam a articulação das exigências econômicas e dos processos de cada conjuntura" (p. 57):. Essa materialidade do Estado no Governo Lula tem em suas raízes a atuação das diferentes forças sociais que não agem mecanicamente, antes, de forma heterogênea, estabelecem a correlação de forças na disputa em torno da concepção de Estado e da definição da agenda do Estado em ação na forma de políticas públicas.

No cenário de emergência de construção do planejamento governamental, alinhado com o novo modelo de desenvolvimento, o governo Lula se deparou com a oportunidade política de organizar objetivos e apontar a direção que contemplasse o projeto político partidário e o enfrentamento à crise econômica brasileira e suas determinantes conjunturais e estruturais, que foram explicitadas principalmente após o ano de 2007. Assim, o planejamento no primeiro decênio do século XXI apresentou-se como decisão política para reforçar um projeto alternativo de desenvolvimento e consolidação de uma hegemonia política, além de necessário para tomada de providências quanto às medidas de contenção à crise em âmbito macroeconômico, monetário e fiscal, ou seja, redução das taxas, redução da carga tributária e expansão do gasto público para bloquear a queda da atividade econômica e estimular o setor produtivo. Nesse contexto, durante o primeiro decênio do século XXI, o PAC foi uma das principais estratégias situadas na perspectiva da planificação no âmbito das políticas públicas, dados seus objetivos, amplitude e orçamento.

Essa retomada da centralidade do papel do Estado como indutor de políticas, estendendo suas diretrizes como influenciador da iniciativa privada, sinaliza um dos principais aspectos de práxis do novo modelo de desenvolvimento. 


\section{ELEMENTOS PARA COMPREENSÃO DO NOVO DESENVOLVIMENTISMO NO CONTEXTO BRASILEIRO}

O movimento de discussão de um novo desenvolvimentismo vem como uma alternativa de terceira via não só para o Brasil, mas para outros países latinoamericanos, como Chile e Argentina, que exerceram um governo buscando equilíbrio entre política social e econômica com vistas ao desenvolvimento com justiça social.

O novo desenvolvimentismo é baseado em experiências bem sucedidas de países do leste da Ásia, em um primeiro momento e, em sequência, na experiência russa e argentina, que, nos primeiros anos deste século, experimentaram bons níveis de crescimento, como resultado de um conjunto de políticas descritas, a seguir, no quadro comparativo da ortodoxia neoliberal e o novo desenvolvimentismo:

\section{Figura 1 - Comparação dos Modelos de Desenvolvimento}

\begin{tabular}{|c|c|}
\hline \multicolumn{1}{|c|}{ Ortodoxia convencional } & \multicolumn{1}{|c|}{ Novo desenvolvimentismo } \\
\hline $\begin{array}{l}\text { 1. Nenhum papel econômico para a nação ou para } \\
\text { estratégias nacionais de desenvolvimento. }\end{array}$ & $\begin{array}{l}\text { 2. A nação é o agente que define a estratégia } \\
\text { nacional de desenvolvimento. }\end{array}$ \\
\hline $\begin{array}{l}\text { 2. Reformas que reduzem o tamanho do Estado e } \\
\text { desregulam os mercados. }\end{array}$ & $\begin{array}{l}\text { 2. Reformas que fortalecem o Estado e regulam } \\
\text { os mercados. }\end{array}$ \\
\hline $\begin{array}{l}\text { 3. As instituiçôes fundamentais para promover o } \\
\text { crescimento são os direitos de propriedade e os } \\
\text { contratos. }\end{array}$ & $\begin{array}{l}\text { 3. A instituição chave para promover o } \\
\text { crescimento é a estratégia nacional de } \\
\text { desenvolvimento. }\end{array}$ \\
\hline $\begin{array}{l}\text { 4. Papel mínimo do Estado no investimento e na } \\
\text { politica industrial. }\end{array}$ & $\begin{array}{l}\text { 4. Papel moderado no investimento e na política } \\
\text { industrial; grande papel na redistribuição. }\end{array}$ \\
\hline $\begin{array}{l}\text { 5. Sem tendências estruturais. } \\
\text { 5. Tendência à sobrevalorização da taxa de } \\
\text { câmbio e ao aumento dos salários abaixo da } \\
\text { produtividade. }\end{array}$ \\
\hline $\begin{array}{l}\text { 6. Liberalização da conta de capital e taxa de } \\
\text { câmbio flutuante. }\end{array}$ & $\begin{array}{l}\text { 6. Taxa de câmbio flutuante mas administrada } \\
\text { para neutralizar sua tendência à } \\
\text { sobrevalorização. }\end{array}$ \\
\hline 5. Crescimento financiado com poupança externa. & $\begin{array}{l}\text { 5. A poupança externa aprecia a taxa de câmbio e } \\
\text { provoca a substituição da poupança interna pela } \\
\text { poupança externa. }\end{array}$ \\
\hline
\end{tabular}

Fonte: Bresser Pereira 2011, p. 32

A situação econômica mundial de crises nos países do capitalismo central trouxe aprendizados e condições de análise para definição de novos caminhos a percorrer, a fim de mitigar os impactos das especulações internacionais na economia brasileira, prevenindo, por exemplo, o desemprego e suas consequências socioeconômicas. Nesse sentido, Bresser Pereira (2004) discorria sobre a necessidade de um desenvolvimentismo contemporâneo para os problemas do século XXI, cujo foco estratégico deveria pautar-se na estabilidade macroeconômica e indicava que "a forma do planejamento deve ser menos 
sistemática e mais estratégica ou oportunista, visando permitir que as empresas nacionais compitam na economia globalizada" (p. 3).

Em contraposição, Sicsú, Paula e Michel (2007) apontavam para a seguinte perspectiva: nem Estado Forte e Mercado Fraco, nem Mercado Forte e Estado Fraco e avaliavam "que a melhor opção é aquela em que seriam constituídos um Estado forte que estimula o florescimento de um mercado forte” (p. 509). A concepção defendida por esses autores foi baseada em estudos keynesianos, pois consideram essa base teórico-analítica a mais elaborada, ao mesmo tempo em que recorrem a economistas keynesianos contemporâneos para explorar a tese de John Maynard Keynes de que "o Estado seria capaz de arbitrar e estimular a concorrência e, além disso, de influir de forma decisiva sobre as variáveis econômicas mais relevantes, como o desemprego, a inflação e a distribuição de renda e da riqueza". (SICSÚ, PAULA e MICHEL, 2007, p. 512) Desse ponto de vista:

\footnotetext{
O novo-desenvolvimentismo [...] não propõe a redução do Estado, mas a sua reconstrução, tornando-o mais forte, e mais capaz no plano político, regulatório e administrativo, além de financeiramente sólido. Propõe, ademais, uma estratégia nacional de desenvolvimento que promova políticas voltadas ao progresso técnico e à introdução de novas técnicas de produção, o desenvolvimento de mecanismos nacionais de financiamento do investimento, políticas econômicas redutoras de incertezas inerentes ao mundo financeiramente globalizado e o desenvolvimento de instituições específicas adequadas ao desenvolvimento (como o desenvolvimento do capital humano através da educação pública). (Idem, p. 515)
}

Em grande medida, o pensamento denominado neodesenvolvimentista propôs alternativas de blindagem da economia e proteção de mercado, indo na contramão do que preconiza o pensamento monetarista neoliberal globalizante e antinacionalista. Com metodologias distintas das sugeridas pelos analistas neoliberais, pelo Banco Mundial e pelo Fundo Monetário Internacional, as bases desse novo desenvolvimentismo caminhou no sentido de sofisticar as várias estratégias de intervenção estatal na economia, com vistas ao fortalecimento da classe empresarial capitalista nacional. Ao lado desses elementos, destacou-se, também, o fortalecimento do sentimento nacionalista como fundamental para a sustentabilidade de um projeto de desenvolvimento. Como sintetizam Sicsú, Paula e Michel (Idem, p. 522)

\footnotetext{
O projeto globalizante é um projeto de desintegração nacional e de enfraquecimento intelectual, econômico e cultural de todos os segmentos de uma sociedade. Os mercados de sociedades globalizadas são, portanto, tragados com facilidade pelos mercados internacionais. Uma alternativa novo-desenvolvimentista visa colocar os mercados nacionais na condição de serem ligados aos mercados internacionais, de tal forma que esta ligação possa trazer sempre muito mais ganhos do que perdas,
} 
em termos de geração de conhecimentos, novos empregos, crescimento e bemestar social.

Por seu turno, o novo desenvolvimentismo levado a cabo nos governos de Lula da Silva buscou consolidar uma inserção soberana internacional, através de um planejamento que envolveu diversos órgãos governamentais, em que o objetivo passava pela internacionalização das empresas brasileiras. No campo estratégico foram colocados temas como o impacto das relações do Mercosul (Mercado Comum do Sul) e ALCA (Área de Livre Comércio das Américas), os limites e possibilidades dos marcos internacionais de cooperação e integração e impactos da inserção econômica internacional para o desenvolvimento nacional. As ações integradas no âmbito da administração pública federal prospectavam agendas diplomáticas nos organismos internacionais com vistas ao reconhecimento, pela comunidade internacional, do novo padrão de desenvolvimento que se buscou concretizar no Brasil e na América Latina.

Ainda sobre o novo desenvolvimentismo Mattei (2011) afirma:

Em linhas gerais, pode-se dizer que o "Novo Desenvolvimentismo" até aqui discutido pretende ser a construção de um "terceiro discurso" entre a ortodoxia neoliberal e o populismo, com o objetivo de implementar um conjunto de reformas das políticas macroeconômicas e das instituições, visando fortalecer tanto o Estado como o mercado e, com isso, tornar o país mais competitivo no cenário internacional. Trata-se, portanto, de um novo projeto que busca transformar o Brasil em um país desenvolvido no longo prazo. ( p. 7)

Na prática, estava anunciada pelo Governo Lula, desde seu Programa de Governo, a preocupação com uma nova concepção de desenvolvimento sob o controle do Estado, que gerasse um balanceamento de interesses nos resultados da gestão socioeconômica, com foco em políticas econômicas estruturantes e políticas sociais de distribuição de renda e interesses de mercado, com vistas a implementar um portfólio de medidas fiscais, tributárias e de investimentos pesados para dar sustentação a setores considerados estratégicos à economia do país.

Sobre esse processo de controle e definição de agenda do Estado sobre a economia, bem assinalam Morais e Saad-Filho (2011) a definição de novodesenvolvimentismo e a sua concepção híbrida, frente aos novos desafios da sociedade capitalista, tecnológica e globalizada, com o objetivo de fortalecimento do Estado Nação e de defesa dos interesses de mercado.

Enquanto alternativa mais difundida, e conforme examinado acima, o novodesenvolvimentismo contém um corpo articulado de políticas econômicas baseadas teoricamente no keynesianismo e no estruturalismo cepalino. Seu objetivo é representar uma nova estratégia de desenvolvimento, superando o nacional- 
desenvolvimentismo tradicional e adequando os seus princípios às novas realidades emergentes da revolução tecnológica e da globalização. Essa política econômica advoga a necessidade de uma ruptura com as políticas macroeconômicas neoliberais, a serem substituídas por novas políticas monetárias, cambiais e fiscais, e subordina a adoção das novas políticas à existência de um projeto nacional para o Estado brasileiro. A defesa da ruptura tem como fundamento a ideia de que as políticas macroeconômicas neoliberais são incompatíveis com a soberania do Estado para implementar uma política econômica atendendo ao objetivo nacional de retomada do desenvolvimento com estabilidade macroeconômica e com um menor custo fiscal. (p. 520)

Outro aspecto colocado nos mandatos de Lula da Silva, como uma parte desse novo desenvolvimento, foi a defesa do crescimento do emprego formal. Sobre isso, Cardoso Junior (2009) assinala uma série de medidas estratégicas colocadas em curso com o objetivo de crescimento do emprego, que levaram em conta um balanceamento entre políticas macroeconômicas e retomada do crescimento, direcionado para o aumento dos salários no emprego formal, gerando aquecimento do mercado interno.

Pudemos identificar ao menos cinco fatores explicativos para a dinâmica recente de assalariamento formal do mercado de trabalho brasileiro, todos eles operando numa mesma direção, provavelmente em simultâneo, ainda que em combinações diversas entre si. Aumento e desconcentração do gasto social, aumento e diversificação do credito interno, aumento e diversificação do saldo exportador, consolidação do regime tributário simplificado para microempresas e empresas de pequeno porte (SIMPLES) e uma maior eficácia das ações de intermediação de mão de obra e de fiscalização das relações e condições de trabalho nas empresas foram os fatores identificados como os principais responsáveis pela trajetória de recuperação do emprego formal no período 2001-2005. (p. 375)

Como se depreende, é colocada em evidência a perspectiva de organização do Estado a partir da afirmação quanto à incapacidade do setor privado de manter-se competitivo no mercado mundial e a incumbência desse Estado de oferecer amparo ao mercado, com a justificativa de que no Brasil sempre foi assim, desde os tempos de ouro do velho desenvolvimentismo, lembrados com saudosismo pela elite industrial brasileira. O Estado brasileiro do primeiro decênio do século XXI contou com vários parceiros para organizar argumentos e rejeitar propostas resistindo às pressões dos mercados hegemônicos, seguindo, assim, no vácuo do exemplo chinês, cujo desenvolvimento se deu basicamente com poupança interna.

No período de 2003 a 2010, ocorreu no Brasil o que pode ser chamado de primeira geração de políticas sociais dentro do novo padrão de desenvolvimento. Elas incluem, principalmente, programas redistributivos, habitacionais, de 
saneamento e infraestrutura urbana, educacionais, entre outros. Essas políticas são justificadas pelo governo como meios para inclusão econômica formal e consideradas medidas emergenciais para reduzir a enorme desigualdade de renda e desmonetarização que assola o povo brasileiro.

Discutir as bases de um novo modelo de desenvolvimento decorre da importância em não separar a análise de políticas públicas sociais e políticas públicas econômicas. Compreender os nexos que se estabelecem na formulação de ambas é ter a capacidade de discernir os interesses em jogo: de um lado, os dos capitalistas e, de outro, os da grande massa de trabalhadores e setores no contexto das relações sociais.

Por sua vez, Castelo Branco (2009) fundamenta que o debate em torno das garantias dos direitos sociais se apresentou, em sua maioria, como manutenção da força de trabalho. Ainda que se possa questionar em que medida as políticas sociais atendem aos interesses capitalistas, de outra parte elas promovem formas de sustentação do sistema e não tocam nas bases do processo de exploração capitalista.

A incorporação dos valores da justiça social, na maior parte dos casos das ideologias burguesas - e esta advertência vale para os novo-desenvolvimentistas - ocorre não como um fim em si mesmo, mas para legitimar ações de técnicos do planejamento econômico, em particular, e dos policy makers, em geral. Em última instância, trata-se de lutar pela manutenção da ordem econômica e da coesão social, e não de transformações estruturais visando a superação do modo de produção capitalista, eternizado e naturalizado como o sistema social por excelência da natureza do bomo economicus. (p. 84)

Por sua vez, para Prado e Meireles (2010), o discurso e a teorização em defesa ao novo desenvolvimentismo com equidade social são apressados e colocam-se como uma estratégia para desconfigurar o discernimento político, confundir a opinião pública e fazer a etapa de transição de Consenso de Washington e Estruturalismo Cepalino para o Novo Modelo de Desenvolvimento com um consenso de maioria:

Não obstante sua pouca originalidade, o atual ideário novo-desenvolvimentista apresenta ao menos duas novas características, relacionadas entre si, que merecem destaque. A primeira se define pela constante limitação do debate ao binômio ortodoxo/heterodoxo bem particular da ciência econômica. Em contraste com as posturas dos autores ligados ao desenvolvimentismo inicial - Raúl Prebisch, Celso Furtado, Juan Noyola Vásquez, entre outros -, que procuravam elaborar suas análises através de uma reflexão que não se confinasse ao plano econômico e que tinham uma clara postura crítica em relação ao pensamento estabelecido, os autores atuais que propõem a construção de um projeto novo-desenvolvimentista para o Brasil se limitam à análise econômica tradicional, cujo traço essencial é o 
de camuflar, com conceitos da "economia vulgar", os interesses capitalistas sob supostos "interesses nacionais". (p. 16)

Dessa forma, o que se tem é a implantação de um modelo com forte componente estratégico, unindo em sua formulação a tentativa de uma atuação simultânea e coordenada do estado em um razoável portfólio de ações e programas equilibrados entre políticas econômicas, fiscais, de proteção social, entre outras.

Os aparatos para evitar as crises cíclicas do capitalismo não foram poucos e os keynesianos contemporâneos, adeptos do novo desenvolvimentismo, se fundamentaram na matriz discursiva em torno da defesa dos princípios de justiça e equidade social. Todavia, no conceito equidade é possível que esteja uma das maiores contradições das bem aventuranças profetizadas pelos neodesenvolvimentistas. Tal conceito foi outrora desenvolvido pela CEPAL e tem origem no pensamento liberal clássico de base keynesiana. Castelo Branco (2009) sintetiza o novo desenvolvimentismo keynesiano:

\footnotetext{
Em síntese, o Estado deve garantir condições macroeconômicas e salvaguardas jurídicas que reduzam a incerteza do ambiente econômico, propiciando um horizonte mais previsível do cálculo de risco do investimento privado, e aumentando, por sua vez, a demanda por fatores de produção, o emprego e os ganhos dos trabalhadores. Assim, o Brasil reduzirá a pobreza e a desigualdade social. O projeto novo-desenvolvimentista de intervenção na questão social, portanto, baseiase no crescimento econômico e na promoção da equidade social via a igualdade de oportunidades. Esta é, grosso modo, a utopia da intelligentsia novodesenvolvimentista. (p. 78)
}

Assim, compreender o novo padrão de desenvolvimento na atuação do Estado Brasileiro no primeiro decênio do século XXI deve ser feito a partir de uma análise integrada entre economia e formulação e implementação das políticas públicas sociais. Essa discussão sobre novo modelo de desenvolvimento num contexto de aprofundamento da crise hegemônica neoliberal em uma conjuntura brasileira de esgotamento das reformas iniciadas na década de 1990 propiciou o resgate da estratégia desenvolvimentista, mas sob um prisma diferente, alinhado com a realidade atual, cujo conceito e prática deram nuances de um novo modelo de desenvolvimento.

Tem-se, portanto, que o Programa de Aceleração do Crescimento (PAC), anunciado em janeiro de 2007, na esteira das ideias já apresentadas em 2002, expressa, em boa medida, um modelo de desenvolvimento econômico cujas bases se fundamentam na perspectiva novo desenvolvimentista em curso no Brasil. 
Essa perspectiva deixa suas marcas também no campo da educação e uma ação de planejamento educacional, coetânea ao Programa de Aceleração do Crescimento, ficou expressa por meio do Plano de Desenvolvimento da Educação (PDE), anunciado também em 2007.

\section{NOVO DESENVOLVIMENTISMO, EDUCAÇÃO E PLANEJAMENTO: O LUGAR DO PDE}

O lançamento do Plano de Desenvolvimento da Educação (PDE) constituiu marco estruturante das políticas educacionais que se delineavam para o período de 2007 a 2010. Com efeito, no segundo mandato de Lula da Silva na Presidência da República, o foco e centralidade dos programas e ações levados a cabo pelo governo federal se deram em torno do PDE, que definiu linhas estratégicas para gestão das políticas educacionais brasileiras do período, preconizando, por meio de largo portfólio de programas e ações, reduzir as desigualdades regionais e intrarregionais em complementaridade ao Fundo de Desenvolvimento e Valorização dos Profissionais da Educação Básica (FUNDEB). Desse modo, os programas e ações que estruturaram o PDE, bem como seus pilares, buscaram aclarar a lógica de fazer política pública do governo de Lula da Silva no campo da educação, proclamando uma visão integrada e de longo prazo, com foco no desenvolvimento, inclusive com um conjunto de ações complexas para fomentar ciência e tecnologia com vistas ao aumento da competitividade internacional e ao crescimento virtuoso da economia no médio e no longo prazo.

De outra parte, o PDE, orientado também pela perspectiva da responsabilização e, por desdobramento, da valorização de aspectos de caráter meritocrático, definiu e se propôs atingir metas de qualidade referenciada no Índice de Desenvolvimento da Educação Básica (IDEB). Tal proposta foi considerada pelo Ministério da Educação como inovação, um avanço, que apontaria para um diferencial entre o Plano Nacional de Educação, aprovado em 2011, e o Plano de Desenvolvimento da Educação. Esse aspecto foi indicado pelo ministro da educação do período, ao discorrer sobre planejamento no governo Lula e a relação entre meritocracia e meta de qualidade.

O primeiro passo para se ter qualquer meritocracia é criar meta de qualidade. Creio que o governo federal teve o mérito de criar indicador de qualidade e meta de qualidade. O Brasil nunca antes fixara meta de qualidade para o seu sistema educacional. Em 2007, por ocasião do lançamento do Plano de Desenvolvimento de Educação (PDE), fixamos tal meta. Isso fez uma grande diferença quando só se havia fixado meta de atendimento, que era o caso do Plano Nacional de Educação 
aprovado em 2001. Agora, temos meta de atendimento e meta de qualidade. (HADDAD, 2010, p. 21)

O PDE, tratado em âmbito federal como PAC da Educação pela característica de um plano executivo, foi delineado com forte conteúdo estratégico. Nesse sentido, a análise dos vários conceitos que sustentam o documento que apresenta as razões, princípios e programas do PDE evidencia que, pelo menos, quatro perspectivas estão ali delineados. A primeira diz respeito ao esforço em estabelecer uma visão sistêmica para combate das desigualdades regionais e intrarregionais no campo da educação. A segunda articula a educação ao desenvolvimento socioeconômico do território. A terceira refere-se à descentralização coordenada para forçar a responsabilização por meio do regime de colaboração. E, ainda, uma quarta perspectiva em que a mobilização social é conduzida como parte da estratégia de accountability, sob a égide da melhoria da qualidade da educação medida por meio do Índice de Desenvolvimento da Educação Básica.

No âmbito da Educação Básica, esse Plano apontava para uma proposta de planificação, expressa de forma mais estruturada no Plano de Ações Articuladas (PAR), que procurava evidenciar a primazia das políticas educacionais no planejamento governamental dos Governos de Lula da Silva. Essas políticas educacionais, por sua vez, afirmavam-se como complementares às ações estimuladoras do desenvolvimento econômico. Dessa forma, houve significativo empenho para a articulação das políticas educacionais em uma planificação de curto, médio e longo prazos, como caminho para se romper com a gestão desengrenada das etapas, níveis e modalidades da educação brasileira.

O Plano de Desenvolvimento da Educação colocou-se como modelo sofisticado de planificação transversal e intersetorial na gestão pública, inserindo o PAR na ordem do dia de todos os entes federados brasileiros. Desse modo, o alcance nacional da planificação em torno das políticas sociais educacionais pode ser considerado um feito inédito na história do Brasil contemporâneo, considerando-se o binômio planejamento e regulação como ações colaborativas dentro do processo de recuperação do poder do Estado brasileiro, em uma conjuntura nacional neodesenvolvimentista.

A presença da responsabilização dos entes federativos estabeleceu o debate sobre um projeto nacional, convocando um federalismo comprometido através da adesão voluntária ao Plano de Metas Compromisso Todos Pela Educação e elaboração e monitoramento do PAR, delineando uma política com mecanismos centralizadores e de intervenção nas instâncias subnacionais. "Podese afirmar que o PDE, na modalidade do PAR, representa uma pretensão sem 
igual do MEC em definir o planejamento educacional dos municípios brasileiros". (PINTO, 2009, p. 329)

Ao mesmo tempo, o aspecto de pactuação presente no PDE, expresso na adesão voluntária ao Plano de Metas: Compromisso Todos pela Educação, regulamentado pelo Decreto 6.094 de 24 de abril de 2007, acabou por produzir um novo marco nas relações entre os entes federados, no regime de colaboração, no comprometimento com um projeto nacional de desenvolvimento e no propósito de constituição de um sistema nacional de educação. No âmbito do PDE, municípios, estados e Distrito Federal participam no que diz respeito ao cumprimento das metas, haja vista a falta de debate público no período de sua elaboração, o que gerou relativa perda de sua autonomia.

Nesse sentido, destaca-se o chamamento para a realização do plano sob o enfoque participativo; houve, contudo, um descompromisso quanto ao esclarecimento das bases e razões do Plano de Metas: Compromisso Todos Pela Educação, o que denunciou a dicotomização entre saber e fazer, anulando o indivíduo como sujeito ativo do processo estratégico.

Em suas potencialidades, o planejamento, por meio do PAR, colocouse de fato como organizador da gestão dos sistemas, colaborando para a implementação de políticas de modo centralizado e coordenado. Entre suas incongruências, o PAR promoveu uma descentralização coordenada, transferindo responsabilidades para os entes em uma célere pactuação, que não considerou a capacidade dos sistemas em nível de federação, gerando, por vezes, constrangimentos que levaram a arranjos e improvisos nas políticas educacionais locais.

Assim, centralização e descentralização colocaram-se como tendências de conciliação de aparentes paradoxos, no intuito de se harmonizarem elementos antagônicos na política educacional no Governo Lula. Isso ocorreu também na efetivação de um planejamento marcado pela regulação gerencialista; com sua metodologia embebida, contudo, de conteúdo burocrático, como a que se faz presente no PAR. Têm-se, desse modo, as marcas do hibridismo e num quadro em que se faz presente a conciliação de modelos mesclados de concepções de planejamento, umas antes dominantes e outras emergentes, presentes no Plano de Ações Articuladas.

A regulação no modo de proceder do Estado encontrou no planejamento condições para efetivar a descentralização coordenada, monitorando, gerenciando e mensurando a evolução de metas, condição importante para o estabelecimento da responsabilização por meio da microrregulação local. Por um lado, a centralidade assumida pelo IDEB enquanto indicador de qualidade nos ajuda a apreender esse nível de responsabilização, mas, por outro lado, também 
estrutura e metodologia de abordagem e avaliação diagnóstica da realidade realizada no âmbito do PAR e, também, reforça essa perspectiva centralizadora da microrregulação local a partir do governo central, por meio do MEC.

As quatro dimensões previstas no PAR - Gestão Educacional; Formação de Professores e dos Profissionais de Serviço e Apoio Escolar; Práticas Pedagógicas e Avaliação e Infraestrutura Física; e Recursos Pedagógicos - são apresentadas como fundamentais para a melhoria da qualidade da educação aferida pelo IDEB e no âmbito destas quatro dimensões o instrumento por meio do qual os governos subnacionais elaboram e registram seu PAR já delimita aspectos da realidade local a serem considerados no planejamento e os parâmetros de avaliação desses aspectos locais. O que se observa é que, apesar da afirmação do Plano Executivo do MEC de que o processo em curso é complementar à implementação do novo modelo de desenvolvimento, o que mais uma vez se constata é sua vinculação a uma concepção gerencial de Estado.

Em síntese, a planificação por meio do PDE e, no que se refere à Educação Básica, também por meio do PAR, traz arranjos que aventam a possibilidade de efetivação de um sistema permanente de planejamento, controle e avaliação, uma vez que se propõe como instrumento contínuo que organiza a gestão municipal com o estabelecimento de compromissos de curto, médio e longo prazos, sendo destacado o papel decisório e indutor da União. Desse modo, o desencadeamento da descentralização coordenada melhoraria as condições de governança da União, oferecendo subsídios para a gestão tático-operacional no curto e médio prazos, e estratégica para o longo prazo. Isso fortalece o poder regulatório estatal nos contornos da regulação nacional e microrregulação local.

\section{À GUISA DE CONCLUSÃO}

As análises aqui desenvolvidas nos ajudam a apreender e compreender dimensões importantes que o planejamento assumiu no contexto da agenda neodesenvolvimentista que se tornou hegemônica nos governos de Lula da Silva no período de 2003 a 2010. Nesse sentido, o planejamento estatal, por meio do PAC e do PDE, traz elementos importantes para se compreender algumas das características que sustentam esse planejamento.

O que se observa é uma matriz discursiva que pretende colocar em evidência uma perspectiva de planejamento de caráter mais global, abrangente, intersetorial. Tal perspectiva é enfatizada tanto no anúncio do PAC quanto nos documentos que orientam e fundamentam o PDE, mas ela já se fazia presente, também, no Programa de Governo anunciado pelo então candidato Lula da 
Silva, durante o processo de campanha eleitoral. Esse caráter abrangente também está presente nas orientações e instrumentos do PAR.

Porém, ainda que se reconheça elementos de uma visão sistêmica da educação, o PDE está igualmente marcado por fortes elementos de uma perspectiva gerencial da gestão da educação, orientada pelo planejamento estratégico, que define e implementa mecanismos que favorecem uma descentralização coordenada, acompanhada de um processo de responsabilização crescente dos governos locais na tarefa de alcançar os índices de qualidade centralmente definidos. E, aqui, também o PAR assume um lugar estratégico no sentido de colocar para os municípios e estados, a tarefa de implementar políticas articuladas às diretrizes, metas, programas e ações definidas a partir do governo central.

Esse movimento no campo do planejamento educacional brasileiro se desenrola coevo a um contexto que, mais uma vez, procurar vincular a educação a um projeto político-econômico de desenvolvimento, porém, agora, o estado assumindo um papel cada vez mais indutor e condutor das políticas sociais e econômicas, dentro de uma agenda neodesenvolvimentista que predominou no contexto brasileiro.

Desse modo, a relação entre desenvolvimento e educação não propõe questionamentos sobre a ação programada do Estado no campo educacional, que se insere em uma crise conjuntural e, também, estrutural. A planificação, em nível macro, esconde as determinações político-econômicas decididas em restritas esferas de poder, ocultas para o cidadão comum. Esta pretende mais do que acudir a crise cíclica capitalista ocorrida durante da era Lula; ao contrário, buscou sustentar as diretrizes educacionais necessárias para a harmonização das tensões no Estado capitalista, por meio de uma falsa neutralidade.

Assim, ainda que o novo desenvolvimentismo implique a presença de novas bases e fundamentos para a atuação do Estado brasileiro, isto não significa que essa atuação se dê fora da égide do Estado capitalista, comprometido com a ampliação do capital e a subordinação dos trabalhadores aos interesses desse capital, o que mantém sua coloração de classe.

Portanto, o PDE e, no seu âmbito, o PAR contribuíram para se reforçar a perspectiva política que vincula a educação e o planejamento educacional ao modelo de desenvolvimento capitalista, em que a realização de uma educação comprometida com um projeto de sociedade emancipatório e de formação para cidadania é relegado a plano secundário. 


\section{REFERÊNCIAS}

BRASIL. Presidência da República. Mensagem ao Congresso Para o Ano de 2008. Disponível em: <http://2.planalto.gov.br/acompanhe-o-planalto/ mensagem-ao-congresso/mensagem-ao-congresso-nacional-2015>. Acesso em: 27 março 2015.

BRASIL, Presidência da República. Decreto n. 6.094/2007 de 24 de abril de 2007. Dispõe sobre a implementação do Plano de Metas Compromisso Todos pela Educação, pela União Federal, em regime de colaboração com Municípios, Distrito Federal e Estados, e a participação das famílias e da comunidade, mediante programas e ações de assistência técnica e financeira, visando a mobilização social pela melhoria da qualidade da educação básica. Brasília: Imprensa Nacional, 2007.

BRASIL. Ministério da Educação. Plano de Desenvolvimento da Educação: razões, princípios e programas. Brasília: MEC, 2007.

BRESSER-PEREIRA, L. C. O Brasil e O Novo Desenvolvimentismo. Interesse Nacional, ano 04, n.13, pp. 76-85, abril/junho 2011. Disponível em: < http:// http://interessenacional.uol.com.br/index.php/edicoes-revista/o-brasil-e-onovo-desenvolvimentismo/>. Acesso em: 27 mar. 2015.

BRESSER-PEREIRA, L. C. O Novo Desenvolvimentismo. Folha de São Paulo, São Paulo, 19 set 2004. Caderno Dinheiro. Disponível em: <http:// www1.folha.uol.com.br/fsp/dinheiro/fi1909200411.htm>. Acesso em: 27 mar. 2015.

CARDOSO JUNIOR, José Celso. Determinantes da recuperação do emprego formal no Brasil: evidências para o período 2001/2005 e hipóteses para uma agenda de pesquisa. Revista de Economia Política. [online]. 2009, vol.29, n.4, pp. 357-376. ISSN 0101-3157.

CASTELO BRANCO, Rodrigo. O novo desenvolvimentismo e a decadência ideológica do estruturalismo latino americano. Oikos. Rio de Janeiro, v. 8, n. 1, p. $7191,2009$. 
COLIGAÇÃO LULA PRESIDENTE, Programa de Governo, 2002. Disponível em: <http://1.uol.com.br/fernandorodrigues/arquivos/.../ plano2002-lula.doc.> Acesso em: 27 março 2015.

FALEIROS, Vicente de Paula. O que é Política Social. São Paulo: Brasiliense, 1991.

HADDAD, Fernando. Ciclo de Palestras: Educação. Brasília: Presidência da República, Secretaria de Assuntos Estratégicos (SAE), 2010.

IPEA. Presidência da República. Estado, Instituições e Democracia: desenvolvimento. Livro 10. Coleção Projeto Perspectivas do Desenvolvimento Brasileiro. Brasília: IPEA, 2010.

MATTEI, Lauro. Gênese e Agenda do Novo Desenvolvimentismo Brasileiro. IV Encontro Internacional da Associação Keynesiana Brasileira (AKB). De 3 a 5 de agosto de 2011, Rio de Janeiro/RJ. 1 CD-ROM.

MORAIS, Lecio; SAAD-FILHO, Alfredo. Da economia política à política econômica: o novo-desenvolvimentismo e o governo Lula. Revista de Economia Política. [online]. 2011, vol.31, n.4, pp. 507-527. ISSN 0101-3157.

PINTO, José Marcelino de Rezende. O financiamento da Educação o Governo Lula. RBPAE., v.25, n.2, p. 323-340, mai./ago, 2009, pp. 323-340.

PRADO, F. C.; MEIRELES, M. R. F. Teoria Marxista da Dependência Revisitada: elementos para crítica do novo desenvolvimentismo nos atuais governos de centro-esquerda latino americanos. In: (Org.) Encruzilhadas da América Latina no Século XXI. Rio de Janeiro: Pão e Rosas, 2010. p. 169-190.

SISCÚ, João; PAULA, Luiz Fernando de; MICHEL, Renalt. Por que novodesenvolvimentismo?. Revista de Economia Política [online]. 2007, vol.27, n.4, pp. 507-524. ISSN 0101-3157.

CECÍLIA CAROLINA SIMEÃO DE FREITAS é mestre em Educação, Professora da Faculdade Presidente Antônio Carlos de Uberlândia. E-mail: freitas. ceciliacarolina@gmail.com 
MARCELO SOARES PEREIRA DA SILVA é doutor em Educação, Professor Titular do Programa de Pós-Graduação em Educação da Universidade Federal de Uberlândia. E-mail: marcelospsilva@hotmail.com

Recebido em fevereiro de 2016

Aprovado em abril de 2016 